\title{
XXXIII. Experimental researches regarding certain vibrations which take place between metallic masses having different temperatures
}

James D. Forbes Esq. F.R.SS.L. \& Ed.

To cite this article: James D. Forbes Esq. F.R.SS.L. \& Ed. (1834) XXXIII. Experimental researches regarding certain vibrations which take place between metallic masses having different temperatures , Philosophical Magazine, 4:21, 182-194, DOI: 10.1080/14786443408648300

To link to this article: http://dx.doi.org/10.1080/14786443408648300

曲制 Published online: 01 Jun 2009.

Submit your article to this journal $₫$

山 Article views: 6

Q View related articles ¿ 
182 Prof. Forbes's Researches on the Vibrations wollich take place will carry thee captive into captivity," i. e. will surely carry thee captive, and הטָׁ (we-oteka atah), "cover thee with a covering," i.e. surely, or completely, cover thee. And it may be noticed, that a particular command thus to cover the ark, seems to have been more needed than a command to daub it with pitch, for navigation in early society is usually performed in boats made of a single tree. It is after some progress in the art, that men begin to cover within and without with a covering of wood.

I have made the above observations, assenting to the opinion to which many would object, that a reference to the existing productions of the climate in which the ark was built, may not be irrelevant to such an inquiry, and believing it can be satisfactorily shown from the Mosaic history of the Deluge, that, in the opinion of its author, the upper strata of the earth have not undergone those great and universal changes which some attribute to the event, and that the present appearances of the earth's surface are in correspondence with the history.

Temple Chambers, Jan. 1834.

I am, Gentlemen, yours, \&c.

W. G. Carter.

XXXIII. Experimental Researches regarding certain Vibrations which take place between Metallic Masses having different Temperatures. By J AMEs D. ForBes, Esq., F.R.SS. L. \& Ed. Professor of Natural Philosophy in the University of Edinburgh.

[Concluded from p. 28.]

\section{Infuence of Figure upon the Vibrations.}

37. I HAVE already noticed the form of the apparatus which I have generally employed. The time of the oscillations and their magnitude depend upon the figure of the vibrating mass, which seems to act just as in the case of a pendulum, or rather of a rocking-stone, the impulse which it receives at each vibration appearing to be given at whatever instant of time the contact of the vibrating edges with the block is effected. This, however, must be understood within certain limits. There must be a decisive interval of time between the two contacts, for if the surface, instead of having two solid angles, as in the bar described above, merges into a continued curve, the vibrations will not take place. If, by any means, however, the period of contact of two portions of the curved surface with the block be prolonged, the impulse will be obtained; as in the case of a silver spoon, used as a bar, where the bowl of the spoon rests upon the block. No vibrations 
will take place if the handle, which is the other point of support, terminate with a round end: should it, however, terminate with an ornamental device, which affords two points upon which it can rock, the necessary impulse will be gained. We presume, therefore, that the time of contact of two points of the metals must be longer than that of the intermediate portions. This condition is readily fulfilled by a vast variety of forms of apparatus, and the rudest masses of metal, such as a poker, when duly heated and placed upon lead, will produce active vibrations. The variations of tone produced upon the apparatus by mechanical interference is easily explained: if a slender rod, with metallic balls at its extremities, be placed across a vibrating bar at right angles to its axis, the time and the arcs of oscillation will be extended, the matter being thrown more to the sides; hence the note will become much lower, and vibrations previously quite insensible will become visible. Again, if while a bar is in a state of active vibration, it be gently pressed from above, the extent of its vibrations will be diminished, and the time will be reduced; hence the note will rise.

38. As it appeared essential to the experiment that the vibration should take place between two points which were longer in contact with the block than the other portions, it seemed important to determine whether the connexion of these points was essential. With a view to determine this, I constructed a bar of lead of the same figure as those which I usually employed, such as A B, tig. 5. I let into it a stud of copper $a$, of which the surface corresponded with that of

Fig. 5.

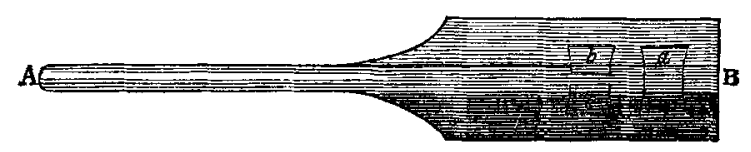

the rest of the bar, and similarly two small ones $b c$, forming the two solid angles upon which the bar was to vibrate, but totally distinct from one another. Whether upon the complete bridge $a$, or upon the divided bridge $b c$, the bar, when heated, and placed upon a block of cold lead, vibrated precisely as if the entire bar had been made of copper. In an early part of this paper I described an experiment, in which the points of the block upon the bar impinged, were completely distinct pieces of metal : see fig. 3. We therefore conclude that the impulse is received by a distinct and separate process at each contact of the bar woith the block, and that 
in neither case is the connexion of these points in any way essential.

39. The use of bars made entirely of the different metals is therefore quite unnecessary. A convenient form of experimental apparatus is suggested by the following construction, which I have employed with success. A heated ring of brass or copper, three or four inches in diameter, being placed sideways upon a ridge of solid lead, with two solid angles, upon which the ring may vibrate (the plane of the ring being horizontal), the action will be extremely energetic, the impulse being given simultaneously at two points, as shown in fig. 6 . If we had the means of firmly clamping two slips of any metal under experiment to the two points of the ring in contact with the block, by means of tightening screws, so as to substitute the material required for Fig. 6. that of which the ring is made, we should have a convenient apparatus, requiring very small pieces of the metals to be tried, and therefore well adapted for experiments on gold, silver, \&c.

40 . The influence of the thickness of the metals employed, and of the extent through which the impulse may be given, early attracted my notice; and I found that thin films of metals of superior conducting power, in the form of leaf, burnished upon the lead block, did not annihilate its characteristic property. The same result in regard to simple gilding was announced by Mr. Trevelyan.

41. We have now to resume the consideration of an important point connected with figure, referred to in an early part of this paper; I mean the groove in the bar or block, which frequently appears essential to the production of a musical note. We have already dismissed the supposition that it has any connexion with the passage of air through that groove, and referred the effect solely to the actually observed increase of velocity in the oscillations: it still remains to explain this result. After a very careful consideration of the phænomena, I am disposed to account for it entirely upon the diminution of the surfaces in contact. It may at first sight be thought that the adhesion of two metallic surfaces must be too small to influence sensibly the time of an oscillation: when the enormous velocity of these oscillations is, however, considered, there can be no room for astonishment. We have shown that there are frequently more than five hundred contacts and separations in a single second. The most minute 
adhesion must therefore clog the energy of the impulse in a way nearly insensible to our ordinary modes of impression: yet cases are not awanting where such adhesion is abundantly sensible, and especially when a metal so soft as lead is one of those employed. It is not difficult to perceive how the position of the groove or separation of pieces (for we have seen that the effect is absolutely independent of the form of the groove, provided the contact of the bar and block for a certain space be avoided) is the most favourable for producing the vibrations. The separation of surfaces may either be in the block, as fig. 7 , or in the bar, as indicated by the dotted lines at $a$ in the same figure: the surface of contact will thus be reduced, as there shown, to about one half. If, instead of this, the space between the solid angles $b$ and $c$ had been reduced to one half, the stabi-

Fig. 7.

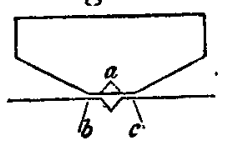
lity of the bar would have been materially changed, and the requisite distance between the points d'appui for producing an active vibration would have been deranged. By cutting out the interior space of contact, the other conditions remain unimpaired, and the adhesion is diminished to almost any required extent; in fact, the note has been most clear and steady when the two points of contact of the block had almost the whole intermediate space removed. The sudden changes of note before alluded to have been very satisfactorily accounted for by Mr. Robison, as arising from a sudden movement of the bar, which, by changing its points of bearing, of course alters the velocity of vibration. The rise of tone which is usual towards the end of the experiment, depends on the diminished impulse received at each stroke, and consequent diminution of the arc of vibration.

42. Indeed the success of the whole experiment depends mainly upon the careful exclusion of adhesion between the two bodies. When merely tried under the most favourable circumstances, as when copper vibrates on lead, the experiment can hardly fail to succeed. With metals less distant from one another on the scale, more delicacy is requisite, and it is then absolutely necessary to avoid any extent of contact in regard to the length as well as breadth of the bar. The form employed originally by $\mathrm{Mr}$. Trevelyan was well adapted for this effect, though the cause seemed not to be attended to: the bar $\mathrm{AB}$ (fig. 8.) rested upon an obtuse angle of the lead-block $\mathrm{C}$ : had the bar been so inclined as to have touched the whole plane $d e$, in many cases no vibration would have taken place, and I have always been at pains to place the bar so that the angle $g$ ef should be nearly equal to $h e d$. If, as

Third Series. Vol. to No. 21. March 1834. 
has been sometimes the case, I used a block of hard metal,

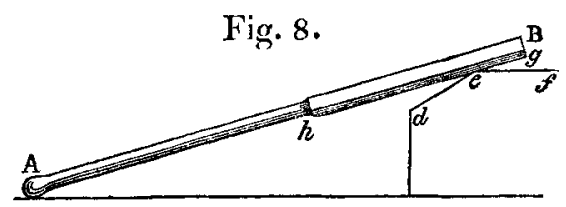

with an angle much more acute than that shown at $e$, and placed a bar of lead upon it, the effect was less favourable than when the angle was more obtuse, and the contact might seem to be greater. The truth, however, was, that in this case the lead, from its softness, was cut by the harder metal, and a new adhesion produced, as in the action of a wedge.

43. These and many other experiments have proved to me, that, to facilitate the vibrations as much as possible, we must have a minimum of adhesion; thus their frequency will be increased and the note raised. Mr. Trevelyan states, that if the surfaces in contact of the two metals be highly polished, no vibration will ensue: this manifestly depends upon the same principle, the adhesion between two perfect planes being well known to be great in amount. I have not met with so strong a case in the course of my experiments.

44. We may conclude this head by noticing that the interference of any foreign matter between the metals (with the exception of the metallic pellicles already mentioned) seems fatal to the experiment. Dust, amalyam, a coating of oxide, or even oil-gilding, stops the vibration. The action of mercury is probably by increasing the adhesion.

\section{Influence of Temperature.}

45. We have seen that the metal of greatest conducting power must have the highest temperature in the combination of two required to produce a vibratory motion. Not merely is there no action between two metals when the temperature of both is the same with air of an apartment, but likewise when both are raised to any higher temperature, for example, that of boiling water.

46. I have not ascertained what is the smallest difference of temperature requisite to produce the effect. It varies, of course, with every different pair of metals. With lead and copper, for example, the vibrations will continue much longer than with lead and tin, although in the former case the temperatures tend more rapidly to an equilibrium.

47. A difference of temperature of $150^{\circ}$ seems to be sufficient for all practical purposes. Being anxious to investigate 
the properties of some metals at a definite higher temperature, I heated several bars in a cast-iron vessel full of sand, along with a thermometer, having a very long scale: this vessel was placed in another containing oil, and when the temperature had risen to $350^{\circ}$, the bars were placed upon cold lead. On one occasion I employed copper, brass, iron and antimony; on another iron, tin, platinum and bismuth. I did not find, however, that the additional temperature thus gained facilitated my inquiries, and it was, in the first place attended with considerable practical difficulties. The experiments, however, confirmed a fact which I had previously suspected, and which forms an exception to what may be considered the general law, namely, that the intensity of vibration is proportional to the difference of temperature of the metals; I found that at $350^{\circ}$ iron was far more sluggish in its vibrations than at $212^{\circ}$. I cannot say that I remarked this in the case of copper, brass, or platinum. The fact, however, hardly admits of doubt. At an early period I had been much perplexed with some anomalies in the vibration of iron. When first taken out of a hot open fire, and just cool enough not to melt lead, its action with that metal appeared very unsatisfactory. This effect was so sensible, that I have frequently repeated with success a singularly paradoxical experiment. A bar of iron heated, suppose to $212^{\circ}$, being placed on a lead block, and the vibrations commenced, if a spirit-lamp was applied to the lower portion of the bar, the vibrations are completely stopped, and may actually be restored by immersing the lead, to which the lamp had been applied, in cold water: these singular effects I have been able to produce several times in succession during one experiment.

48. The same effects, though less striking, have been produced with zinc instead of iron, which vibrates with considerable difficulty when the temperature is raised above $212^{\circ}$. I have been disposed to consider that every metal has its own most favourable temperature, though on what principle it is not so easy to explain.

49. It is probable that the softening of the heated metal diminishes the resiliency of the two bodies when impact takes place. I do not think that it is attributable to the softening of the lead, for I have found that iron is more disposed to vibrate on platinum when at a moderate temperature, than when red hot. The effect may, however, be connected with the theory of the vibration.

50. Having now discussed the phrnomena of sound, and of the vibrations to which we have shown these sounds to be referrible, we shall next consider 


\section{The Theory of the Phanomena.}

51. It is a curious fact how imperfectly the interest attached to the phænomena observed by Mr. Trevelyan, seems to have excited enlightened curiosity. Indeed, an explanation of great simplicity, and which appeared to account for the more conspicuous phænomena, was pretty generally acquiesced in, and seems to have acted as a barrier to further examination. It was, I believe, first thrown out by Sir John Leslie, on considering the simple facts which were brought to light by $\mathrm{Mr}$. Trevelyan's experiments, that they might be explained by the expansion of the cold metal at the instant of contact with the warm one, which might be supposed to give a sufficient impulse for sustaining a new vibration. Even at first sight it does appear very difficult to conceive how, when the vibrations are increased to 500 or more in a second, a process depending upon so slow an operation as the conduction of heat, should cause the metal to expand and contract successively by a finite quantity. The effect has every appearance of being one of active and almost instantaneous repulsion, and bears no resemblance whatever to the slow mechanical elevation of the surface by the process of expansion. But such inferences are often erroneous; it became, therefore, most important to inquire how far the hypothesis was applicable to various forms of the experiment, particularly to the different properties in this respect of various substances.

52. This more difficult task was undertaken by Mr. Faraday; and in a lecture on the subject which I was fortunate enough to hear at the Royal Institution in April 1831, he freed the subject, (as we have already seen,) from many of the difficulties with which it had been surrounded, and illustrated the theory which he supported in that happy style for which he is so remarkable.

53. The principle which he adopted was fundamentally the same as that of Sir John Leslie, but he added an explanation of the influence of the properties of different metals upon the phænomena. According to his view, the hot metals should have a higher conducting power, and a smaller expansion by heat, than the cold one, and the arrangements of the metals as vibrators depend, according to him, upon this principle. To employ the official statement of his views contained in the Royal Institution Journal *, "s the superiority of lead, as the cold metal, was referred to its great expansive force by heat, combined with its deficient conducting power, which is not a fifth of that of copper, silver, or gold; so that the heat ac-

* New Series, No. IV. pp. 119, 129. 
cumulates much more at the point of contact in it, than it could do in the latter metals, and produces an expansion in that respect proportionally greater."

54. I certainly approach with deference any opinion expressed by a philosopher of the reputation and acuteness of Mr. Faraday, and nothing but a strong conviction, entertained chiefly upon the general grounds already alluded to, could have induced me to spend my time in an investigation which he considered decided upon some of the simplest principles of physics. My dissatisfaction with the explanation increased the more I thought of it, and the more closely I analysed the natural process which he had traced out. I consider it essential to point out on what grounds I dissented from a theory supported by two of the first names in British science, before I proceed to give any opinion of my own, which may perhaps be liable to equally strong objections, but the data of which are not the less valuable as physical facts.

55. Waving all minor objections, I conceive that the process of the communication of heat, and consequently its effects, would be very different from what has been stated in the passage just quoted. Let fig. 9. represent on an exaggerated scale the presumed state of the apparatus in the middle of an oscillation: the hot bar A, whilst performing its vibration upon one of the solid angles $a$, has expanded a portion of the cold block $\mathrm{BC}$ into a hillock at $d$ : when

Fig. 9.

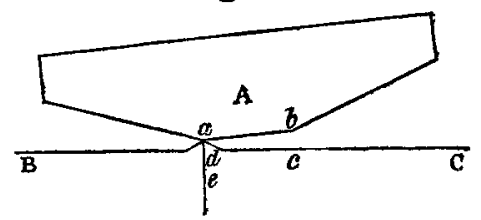
the semi-vibration is completed, the angle $b$ of the bar will touch the block, and raise a new hillock at the corresponding point $c$, whilst the elevation at $d$ subsides; and so on alternately. Let us conceive that $d e$ is the finite depth to which heat is communicated in the minute portion of time occupied by a semi-vibration, a depth so small as to be inappreciable by the senses, and insignificant compared to the distances between the points of impact $d c$. The elevation or height of the hillock $d a$ is the amount of expansion of the element $d e$, by the accession of temperature received during a semi-vibration : the question is, what relation will this expansion, or acquired vantageground for the commencement of a new vibration, bear to the nature of the block $\mathrm{BC}$, considering the nature and temperature of the bar A, and the initial temperature of the block, to be constant? It surely requires no elaborate demonstration to prove that the amount of caloric which passes into the block 


\section{Prof. Forbes's Researches on the Vibrations which take place}

must increase with the conducting power of the material. Upon the very fundamental axioms of the theory of heat, the amount of caloric which passes from a molecule $\mathrm{A}$ into a molecule $\mathrm{B}$, in an infinitely short interval of time, is proportional to the difference of the temperatures of the molecules* combined with the conducting power of B (that of A being considered constant), and with the element of the time. Or, putting the temperature of $\mathrm{A}=\alpha$, that of $\mathrm{B}=\beta$, and its conducting power $=\mathrm{K}$, and the element of time $=d t$, the proportion of caloric transmitted will be

$$
(\alpha-\beta) \text {. K. } d t \text {. }
$$

56. It appears to me indubitable, that whether the time be short or long, the quantity of caloric transmitted, and the consequent amount of expansion, must increase with $\mathrm{K}$. The idea of an accumulation of heat at the surface producing more effect than a rapid communication with the interior, is obviously an oversight. For if the heat be accumulated at the surface, the temperature of that surface, rapilly approaching to that of the source of heat $A$, will, in the same ratio, diminish the amount of heat received; and it can require no demonstration to prove, that the expansion depends solely upon the amount of temperature acquired above its initial temperature by the prism of metal, which by its expansion is to raise the bar from $d$ to $a$, (fig. 9.) modified of course by the amount of expansion proper to any substance employed + . Consequently this amount, or $d a$, will be proportional to

$$
\frac{\mathrm{E}}{c}(\alpha-\beta) . \mathrm{K} \cdot d t,
$$

E being the measure of expansibility, $c$ the capacity for heat of the substance, taken by volume not by weight.

* For such small differences of temperature the Newtonian law may be viewed as absolutely accurate.

$\uparrow$ In fact, let $\mathrm{A} B$ represent the surface of the body, receiving heat at the point $a$; and let $a b$ be a line normal to the surface, consequently the expansion of which is to produce the elevation at the point $a$. The ordinates of the curve $c d$ may represent the acquired temperatures, and the total acquired

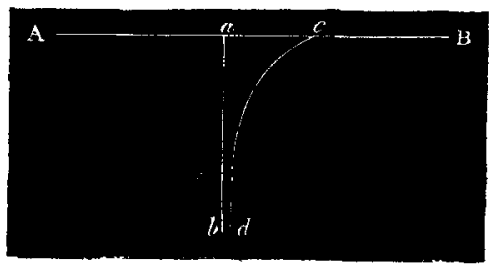
temperature will be denoted by the area of the curve, to which likewise the expansion will be proportional without regard to its particular form, (the distribution of heat,) which will vary with the conducting power; and although it is very possible that the ordinate $a c$ of the curve may be greatest in a bad conductor, it is very easy to seo that the total area never can. 
57. Hence it appears to be quite obvious, that as far as conducting power is concerned, both bar and block should have it in the highest possible degree. It would be quite essential, too, upon this explanation, that the cold metal should expand more than the hot one, otherwise the loss of elevation by the contraction of the warm metal will equal or exceed the vantage-ground for the new vibration gained by the expansion of the cold one. By both these criteria Mr. Faraday's theory seems to be deficient: I need only point out the position of zinc, which, with greater expansibility than lead or tin, occupies so bigh a place in the list of vibrators, and cannot be used as the cold metal with any other except silver: according to the theory, zinc ought to vibrate far better upon zinc than upon lead or tin. Silver, again, vibrates upon cold iron, although its expansibility is a half greater. Such facts as these seem absolutely unaccountable upon the hypothesis of expansion.

58. The objections which I took in limine to the explanation of Sir John Leslie and Mr. Faraday, (which was adopted by Mr. Trevelyan in the paper printed in the Edinburgh Transactions,) were strengthened, and I may say rendered decisive, by my subsequent experiments, the results of which have been detailed in a previous part of this paper. For nearly two years I have been constantly expecting to see some systematic examination of these curious facts; but the public seems to have rested satisfied with the ascription of them to a simple and acknowledged effect of heat. They have hardly been noticed in the Journals, and foreigners complain of the few data afforded by English works on the subject. An article by Professor Müncke of Heidelberg, in Poggendorff's Annalen*, consists chiefly of the translation of a very brief notice, which I had published in the Edinburgh Journal of Sciencet, but contains no new observations. Having shown the reasons which led me to dissent from the opinions at first proposed, I shall now explain the views which I have been led to entertain from the study of the phænomena.

59. I shall first recapitulate the general laws at which we have arrived.

1st, The vibrations never take place between substances of the same nature. Art. 13.

2nd, Both substances must be metallic. Art. 14.

3rd, The vibrations take place with an intensity proportional (within certain limits) to the difference of the conducting powers of the metals for heat (or electricity), the metal having the least conducting power being necessarily the coldest. Art. 36.

$$
\text { * 1832, No. III., p. } 466 . \quad+\text { New Series, No. XI. }
$$


4th, The time of contact of two points of the metals must be longer than that of the intermediate portions. Art. 37.

5th, The impulse is received by a distinct and separate process at each contact of the bar with the block, and in no case is the metallic connexion of the bearing points in the bar, or those of the block, in any way essential. Art. 33 .

6 th, The intensity of the vibration is (under certain exceptions) proportional to the difference of temperature of the metals. Art. 47.

60. In order to satisfy these various conditions, we shall find that the range of hypotheses is not great. During my experiments I was for a long time attached to the idea of a thermo-electric action. The hypotheses which $I$ assumed to explain the steps of it I was forced successively to abandon, and the total want of connexion of the order of the metals as vibrators with their thermo-electric properties (and especially the absolute inertness of antimony and bismuth), convinced me, after a long series of experiments, undertaken with this view, that I was wrong.

61 . The strict and simple connexion with the conducting powers of the metals for heat and electricity afforded a firm basis for speculation, and I was soon forced to consider heat as the sole agent in the case, all idea of electricity being necessarily abandoned, as soon as it was established that thermoelectricity had no share in the action. The general laws above quoted seem to be all resolvable into this, "That there is a repulsive action exercised in the transmission of heat from one body into another, which has a less power of conducting it." These repulsions only take place between bodies having a certain amount of conducting power, below which some metals fall; it must be excitable in a most minute space of time; and is energetic in proportion to the difference of conducting power of the substances, and to their difference of temperature.

62. It seems most probable, therefore, that the repulsive action alluded to, depends on the internal motions of heat itself. It were easy to frame a hypothesis which would be sufficiently plausible, and represent the phænomena. I forbear, however, from doing it at present, because our ignorance of the internal constitution of bodies, and the mechanical process of the conduction of bodies, is such as to render hypothetical reasoning upon such data almost useless. That repulsion does exist in the case of heat can hardly admit of a doubt. The reason that we cannot render it visible in ordinary cases, is no doubt that the repulsion of the heat in two approximate molecules of bodies is to small too be weighed in our balances. 
Consequently, two bodies equally heated and placed together, manifest no sensible repulsion. In such a case every portion of heat is kept in equilibrium by the equal and opposite repulsions of the molecules on each side of it, which is the case when heat is uniformly diffused through a body, and which is manifested by that universal tendency to diffusion. Hence the element of heat is in a state of equilibrium, and the only force which could be excited successfully to produce a separation, would be between the heat residing in the last molecule of one body, and the first of a separate one in contact with it, but not bound to it by cohesive attraction. Suppose, however, this second or free body cooler than the other, a current of heat will be immediately created, which, as it is more or less easily receiyed by the cold body than parted with by the hot, will create a stagnation, or a rarefaction of the elements of heat, respectively; in the former case producing a repulsive action, or recoil through the whole string of elements set in motion; in the latter we are led to anticipate that the action would be attractive. If this view be correct, (and being theoretical, I do not attach great importance to it,) it is easy to see why repulsion takes place only when the cool body has less conducting power than the hot, and why the repulsive energy depends on the difference of these conducting powers. In the case of very bad conductors, such as antimony and bismuth, I conceive that the current has not had time to establish itself.

63. In the case of electricity, a remarkable similarity of effect is observable, depending on the conducting power of the material through which it passes. All those remarkable repulsive actions which produce destructive effects in the case of lightning, take place during the accumulation of impulses in bad conductors*.

64. I have been led to entertain the idea of a new species of mechanical agency in heat, not from a love of introducing novel principles, but after having been driven by experiment from the hypotheses to which I was at first entirely attached. Although the mechanical effect of the repulsive power of heat cannot be said ever to have been demonstrated, experiments are not wanting which seem to be quite inexplicable without its aid, or some other principle not yet recognised in science.

65. Several ingenious French experimentalists have fur-

* I might point out another analogy in the sudden and forcible action of the hydraulic ram, where the accumulated effect of small impulses produces sudden and intense results, but $I$ am afraid of extending unwarrantably such speculative analogies. The two preceding paragraphs of this paper have been somewhat modified since it was first read.

Third Series. Vol. 4. No. 21. March 1834. 2 C 
nished us with facts, which, though not completely established as belonging to any peculiar class of phænomena, and therefore not generally admitted into systematic works, are not the less worthy of notice. 'Those which bear most directly on our present speculation were observed by M. Fresnel*; namely, the repulsion of disks of mica, of which one was placed at the extremity of a delicately suspended needle in vacuo, and when the disks were in contact, heated by means of a ray of solar light concentrated by a lens. M. Saigey $\dagger$ has also described a class of similar phænomena observed by himself, with a considerable number of metals, which after rejecting the influence of aerial currents, of electricity, magnetism, \&c., he ascribes to the repulsive action of radiant heat at sensible distances. There are several other experiments on record which seem to require a similar explanation, but I apprehend that the present are the first to establish the existence of some species of mechanical repulsion in the propagation of heat, a principle which can hardly fail to be applicable to the explanation of many natural phænomena.

Greenhill, Edinburgh, Feb. 19, 1833.

XXXIV. Reply to Mr. Earnshaw's Remarks on the "Principle of Least Pressure." By the Rev. H. Moswley, B.A., Professor of Natural Philosophy in King's College, London.

To the Editors of the Philosophical Magazine and Journal.

Gentlemen,

I submitting to the consideration of Mr. Earnshaw the following answer to his remarks on my paper purporting to contain the demonstration of a new statical principle, which I have called that of least pressure; I beg to suggest to that gentleman that the obscurity of which he complains is perhaps in some respect attributable to the nature of the subject under discussion. The theory of statical resistances has always been considered among the most difficult and complicated of those subjects which lie within the range of exact science, yielding itself most unwillingly and ungraciously to the control of analysis, and such, in its nature, as cannot be submitted to the test of experiment.

It is nevertheless a subject entering, more or less, into the complete discussion of almost every question $\ddagger$ that can occur

* Annales de Chimie et de Physique, xxix. 57. and 107.

+ See several successive articles in the Bulletin des Sciences Mathématiques, tom. ix. See also Pouillet, Elémens de Physique.

\$ There is practically scarcely any case of equilibrium, among the forces 